\title{
AMYLOID ARTHROPATHY (SHOULDER PAD SIGN) IN A PATIENT ON DIALYSIS DUE TO MULTIPLE MYELOMA
}

Daniela Gomes Chicre Oliveira ${ }^{1, \star}$, Carlos Eduardo Garcez Teixeira ${ }^{1}$, Marina Ferreira Simões ${ }^{1}$, Isabela Tambelli Pires Cardoso ${ }^{1}$, Ana Carolina Armiliato Bogoevich ${ }^{1}$, Luã Portela Carvalho ${ }^{1}$, Luísa Becker Savastano ${ }^{1}$, Eliane Maria Ingrid Amstalden ${ }^{1}$, Lilian Tiemi Hirata ${ }^{1}$, Manoel Barros Bertolo ${ }^{1}$, Alisson Pugliesi ${ }^{1}$

1.Universidade Estadual de Campinas, Campinas (SP), Brazil.

*Corresponding author: danielachicre@gmail.com

\section{BACKGROUND}

Amyloidosis is a heterogeneous group of diseases characterized by the extracellular deposition of low molecular weight proteins in tissues. Specially the AL type (mostly associated with multiple myeloma) and beta-2-microglobulin amyloidosis (as a consequence of dialysis) can affect the osteoarticular system. The "shoulder pad" sign is a rare pathognomonic finding for musculoskeletal involvement of the disease and could happen in both types of amyloidosis.

\section{CASE REPORT}

A 58-year-old male, diagnosed with multiple myeloma one year and half ago, sought medical help referring shoulder enlargement with limited range of motion and pain (Figure 1). He was under chemotherapy with cyclophosphamide, thalidomide, dexamethasone and pamidronate, with partial response and hemodialysis for 8 months because of kidney failure. Shoulder ultrasound showed accumulation of hyperechogenic material between muscles fibers. Tomography showed glenohumeral joint effusion, and volumetric shoulder increase resembling the "shoulder pad" sign (Figure 2). Biopsy was performed and evidenced eosinophilic and amorphous material deposits. Congo red stain was applied to the tissue and showed strong positivity in salmon color, under polarized light it exhibited apple green birefringence confirming the diagnosis of amyloid deposit (Figure 3).

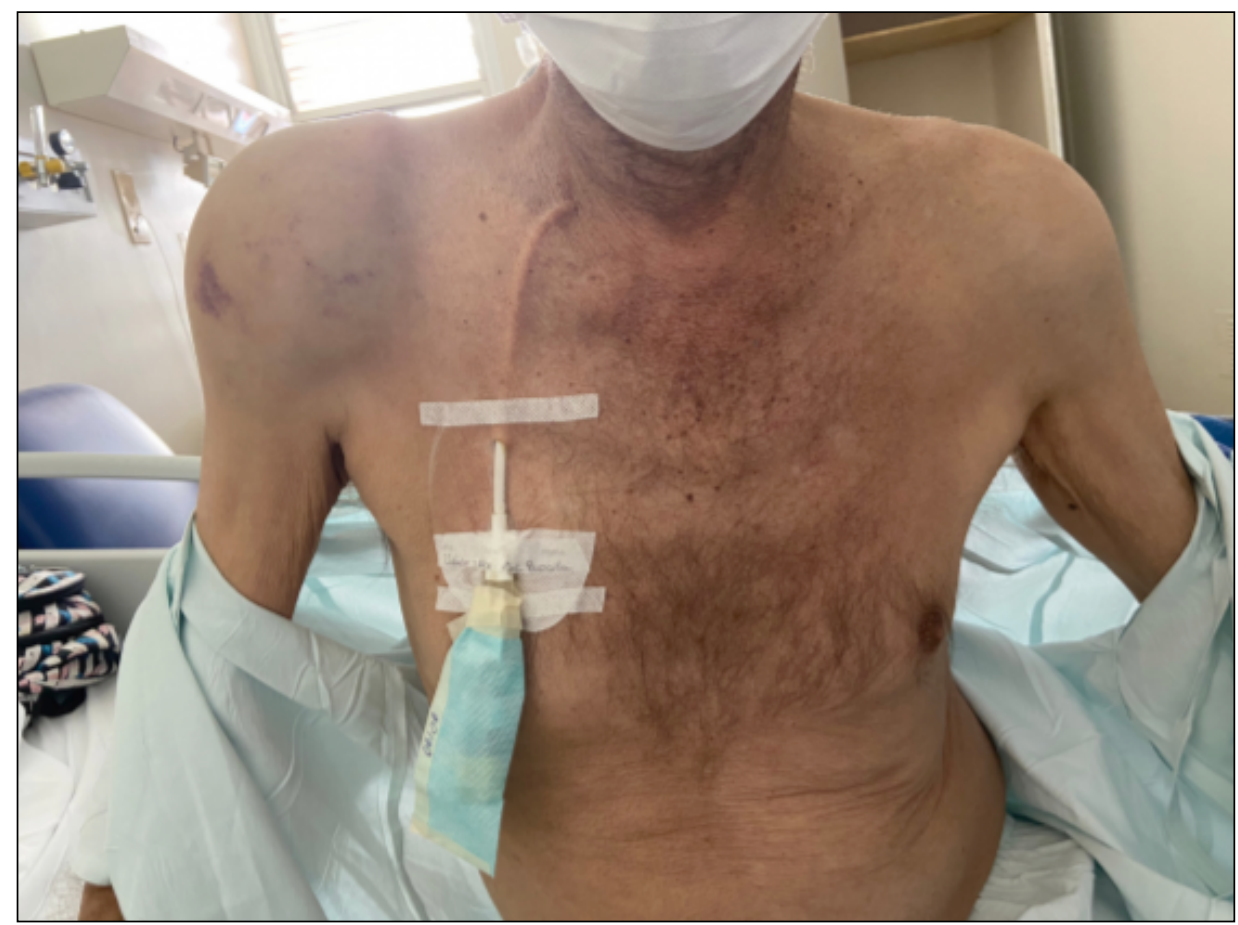

Figure 1. Shoulder pad sign. 


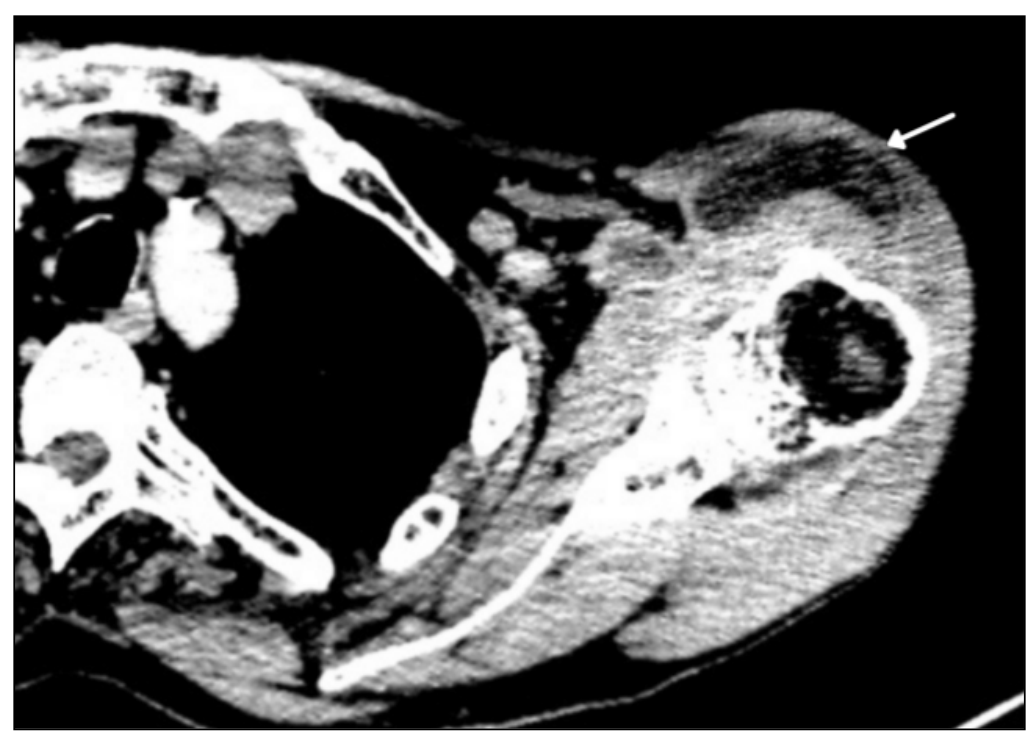

Figure 2. Tomography demonstrating a hypodensity area between muscle fibers and shoulder enlargement due to soft tissue thickening.

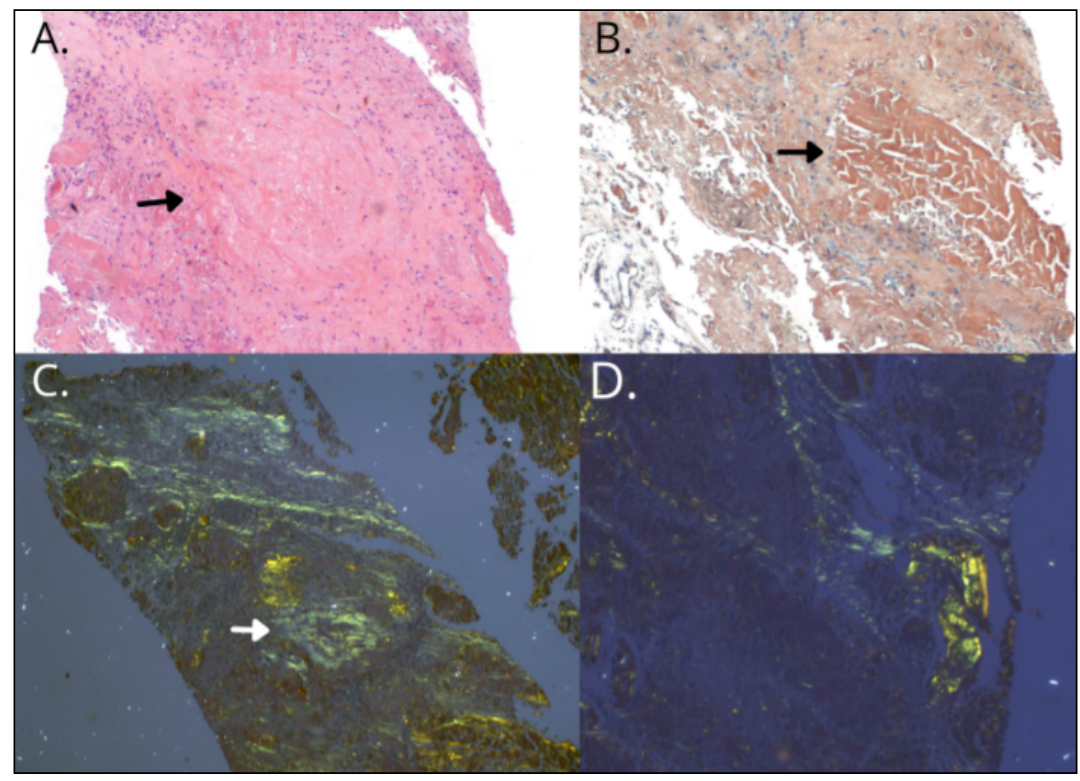

Figure 3. (A) Muscle biopsy with hematoxylin and eosin staining showing eosinophilic and amorphous material deposits suggestive of amyloid infiltration; (B) Congo red stain with positivity in salmon color; (C and D) Congo red stain under polarized light showing apple green birefringence.

\section{CONCLUSION}

In face of joint complaints and shoulder enlargement in patients with myeloma and/or chronic kidney disease stage 5, the rheumatologist should remember the possibility of amyloid arthropathy. Although in the case above it was not possible to differentiate the amyloid protein (AL or beta-2-microglobulin), the clinical context suggests amyloid AL because of its increased predilection for soft-tissue deposition.

\section{KEYWORDS}

Shoulder pad, Amyloidosis, Arthropathy, Myeloma, Dialysis. 